\title{
Characteristics and evaluation outcomes of genomics curricula for health professional students: a systematic literature review
}

\author{
Divya Talwar, MPH, BDS ${ }^{1}$, Wei-Ju Chen, PhD, CHWl ${ }^{1}$, Yu-Lyu Yeh, PhD ${ }^{1}$, Margaret Foster, MS, MPH ${ }^{2}$, \\ Salah Al-Shagrawi, $\mathrm{MS}^{1}$ and Lei-Shih Chen, $\mathrm{PhD}, \mathrm{MCHES}^{\circledR}{ }^{1}$
}

Purpose: With the increased advances in genomics, leading health authorities have advocated the importance of incorporating genomics content into health professional school education to ensure those students achieve adequate genomic competencies. Yet, information regarding the genomics education status for this particular group is lacking. We conducted a systematic literature review to summarize the characteristics and evaluation outcomes of genomics curricula for health professional students.

Methods: Medline (OVID), EMBASE, CAB (EBSCO), Global Health, MedEdPORTAL, Google Scholar, and Web of Science were searched for relevant articles.

Results: Forty-one articles met our inclusion criteria. The majority were conducted in the United States and offered to pharmacy and medical students (the number of students ranged from 10 to 2674).
The effects of genomics curricula on students' knowledge $(n=36)$, attitudes $(n=16)$, self-efficacy $(n=14)$, comfort level $(n=4)$, intention $(n=3)$, motivation $(n=3)$, and behavior $(n=2)$ were assessed. Although those results were generally positive, $68.3 \%$ of the genomics curricula were not theory-based, and most studies did not report follow-up data (85.4\%).

Conclusion: Our findings provided information on the existing genomics curricula available for health professional students.

Genetics in Medicine (2019) 21:1675-1682; https://doi.org/10.1038/s41436018-0386-9

Keywords: genetics; genomics; genomics education; genetics education; health professional students

\section{INTRODUCTION}

Before the mapping of the human genome achieved by the Human Genome Project (HGP) in 2003, genetic competencies for health professionals were limited to the management of single-gene disorders such as cystic fibrosis, Huntington disease, and sickle cell anemia. ${ }^{1-3}$ Only limited and certain specialty medical fields (e.g., genetics, pediatrics, obstetrics, and gynecology) provide direct and/or indirect geneticsrelated services and education. Since the completion of the HGP, genetic knowledge has been applied to nearly all diseases, exceeding far beyond single-gene diseases. ${ }^{4}$ One of the obvious examples is that there has been a $275 \%$ increase in the number of available genetic tests for various diseases since the completion of the HGP. ${ }^{5}$

To keep up with the accelerating and continual advances in genomic science and technology, health professionals are called upon to develop comprehensive competencies in genomics. To address this issue, leading organizations in the United States and Europe have outlined genomic competencies for a variety of health professionals. These include competencies for all disciplines, such as the Competencies for All Healthcare Professionals developed by the National Coalition for Health Professional Education in Genetics (NCHPEG) and discipline-specific competencies, such as the Essential Nursing Competencies and Curricula Guidelines for Genetics and Genomics proposed by the American Nurses Association. ${ }^{6,7}$

There are two complementary viewpoints to consider in fostering the development of a genomically competent health workforce. The first viewpoint is to train practicing health professionals in genomics to optimally educate and treat patients as well as provide timely referrals to genetic professionals. Continuing education has commonly been utilized for training this group. The second viewpoint is to contribute a genomically competent health workforce by educating health professional students in genomics. ${ }^{5,8}$ In doing so, when those students graduate, they are equipped with essential genomic competencies to treat patients and can quickly grasp rapid advanced genomic information. Professional associations and organizations, such as the Association

${ }^{1}$ Department of Health and Kinesiology, Texas A\&M University, College Station, TX, USA; ${ }^{2}$ Medical Science Library, Texas A\&M University, College Station, TX, USA. Correspondence: L-S. Chen (lacechen@tamu.edu) 
of Professors in Human and Medical Genetics, the European Society of Human Genetics, and the National Academy of Medicine (formerly called the Institute of Medicine) have asserted the importance of incorporating genomics-related content into health professional or health science school education to ensure those students achieve adequate competencies in genomics. ${ }^{9-11}$

Currently, genomics education status for practicing health professionals has been reported and summarized in a systematic review. ${ }^{12}$ While it has been advocated that health professional students need genomics education, information regarding the genomics education status among this particular group is lacking. To this end, the purpose of this systematic literature review is to summarize the existing genomics education curricula available to health professional students. In particular, we seek to address the following questions: (1) What are the characteristics of existing genomics education curricula for health professional students? (2) How have these genomics education curricula been evaluated? and (3) What are the evaluation findings for those genomics education curricula?

\section{Article search and selection}

MATERIALS AND METHODS

To plan and manage the literature search, Garrard's matrix method $^{13}$ was utilized. In particular, this study consisted of three steps to search and select articles (shown in Fig. 1). First, an initial search of four databases, including Medline (OVID), EMBASE, CAB (EBSCO), and Global Health, was conducted to identify abstracts focusing on genomics or genetics curricula for health professional students. The search terms used were "genomics," "genetics," "education," "training," "curriculum," "curricula," "health occupation students," "graduate education," "medical education," "dental education," "nursing education," "pharmacy education," "public health professional education," "student," "undergraduate," "graduate," "doctoral," "nursing," "medical," "pharmacy," and "public health." For this comprehensive review, the key terms and Boolean search terms were utilized. The inclusive dates for the search were January 1, 1990 to October 6, 2017. The year 1990 was chosen because this is when extensive work in genomics was initiated (starting with the HGP). Furthermore, we also searched through MedEdPORTAL, an open-access peer-reviewed journal published by the Association of American Medical Colleges and American Dental Education Association, ${ }^{14}$ to identify additional studies. The identified abstracts from the literature search were exported to Refworks for further coding and elimination of duplicates.

The second step involved identifying the abstracts that met the inclusion criteria: (1) articles were peer-reviewed and written in English; (2) studies were published after 1990 because 1990 was the beginning of the HGP; (3) participants were undergraduate or graduate health professional students in disciplines such as medicine, pharmacy, nursing, physician assistant, and allied health; (4) studies reported both genomics education curricula and evaluation findings; and (5) genomics curricula were clinically relevant because laboratory-focused or basic genomic curricula might not be applicable in a clinical setting. Abstracts were excluded if they met the exclusion criteria: (1) a focus on healthcare professionals, fellows, and/or residents rather than on students; (2) mixed types of participants (e.g., students and health professionals/ fellows/residents) and no separate findings for the student group; (3) continuing education programs; (4) non-clinically relevant, laboratory-focused, or basic genomics curricula; (5) lack of comprehensive evaluation outcomes; and (6) reviews, editorials, and conference abstracts. A total of 29 studies were identified in this step.

To ensure a comprehensive literature review, as the final step, references as well as the studies conducted by the first and last authors of those articles identified in the second step were searched via Google Scholar and Web of Science. Using this technique, 12 additional articles were identified. Accordingly, 41 articles formed the final sample for this systematic literature review. To ensure the reliability of the article selection process, two authors (D.T. and S.A-S.) independently reviewed and screened abstracts and articles. Disagreements and concerns were discussed between the two authors to reach a final agreement.

\section{Data extraction and synthesis}

Data from the included articles are organized in a matrix shown in Table S1, which consists of three parts. Part I summarizes program characteristics, such as author's name, publication year, country where education was conducted, targeted students, theoretical basis of the course content, educational approaches, and length of curricula. Part II includes program evaluation characteristics, including evaluation design and tools, data analysis, as well as main findings. When studies presented both significant and non-significant results, only the significant findings were reported as major findings. Yet, when studies only had descriptive data, we reported those descriptive results. Two authors of this manuscript (D.T. and Y.Y.) independently coded part I and part II of the matrix. The inter-rater reliability was 0.82 calculated using Gwet's AC1, indicating a strong consistency and agreement. ${ }^{15}$ The last section of the matrix, part III, showed the methodological quality score (MQS). The MQS was developed based on past literature ${ }^{12,16-18}$ by the research team, and it presented the overall methodological assessment of each included study with a theoretical range of 0-8 points. It evaluated the sample size, length of the educational courses, theoretical basis of the curricula, and follow-up data collection (shown in Table 1).

\section{RESULTS}

The characteristics of genomics education courses

As shown in Table S1, among the 41 reviewed studies, ${ }^{11,19-58}$ the majority were in the United States $(n=35 ; 85.3 \%)$ and the remaining were in the United Kingdom $(n=2 ; 4.9 \%)$, the Netherlands $(n=2 ; 4.9 \%)$, Canada $(n=1 ; 2.4 \%)$, and China $(n=1 ; 2.4 \%)$. The years of publication ranged from 1990 to 


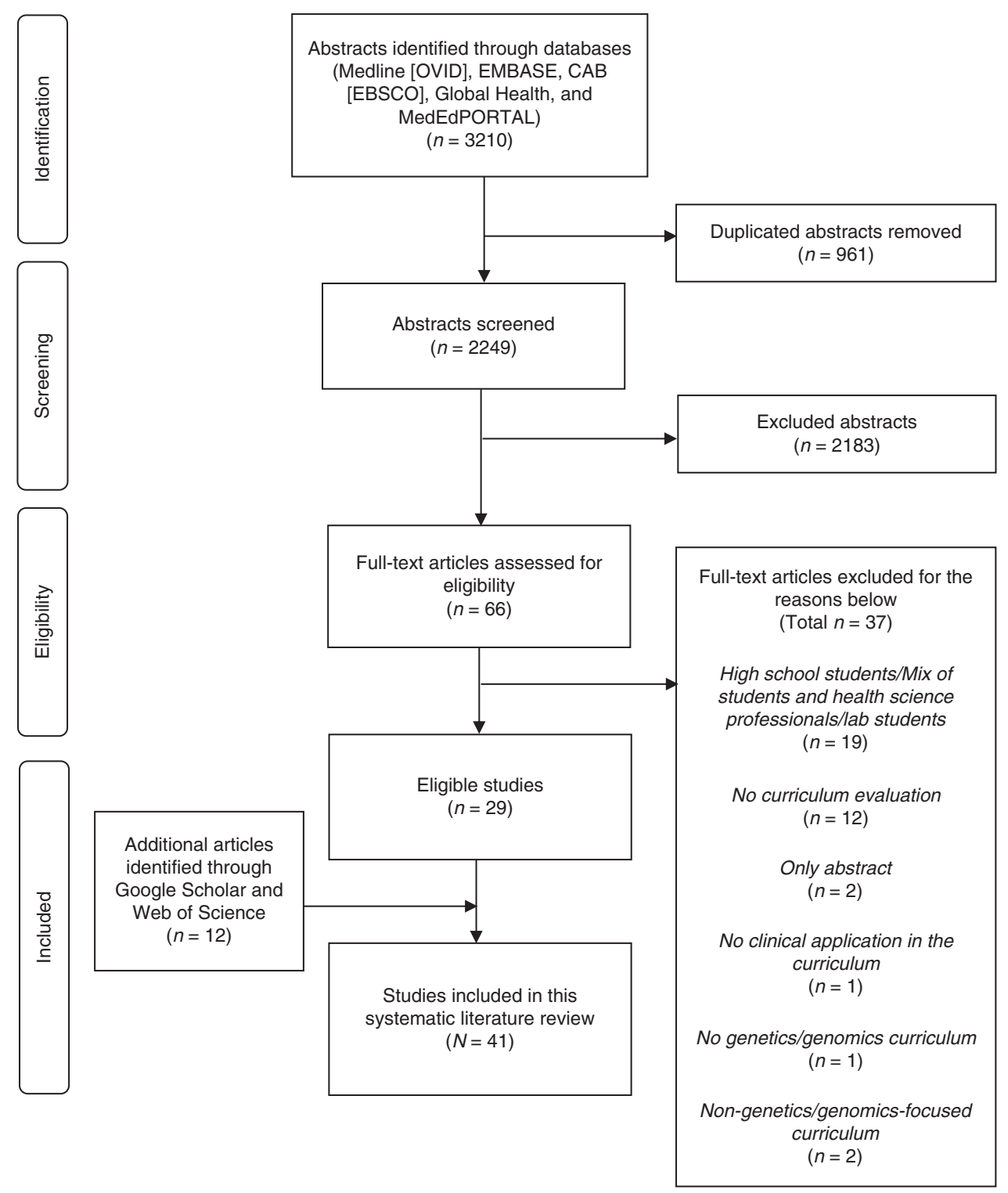

Fig. 1 Article search and selection procedure.

1999 ( $n=2 ; 4.9 \%), 2000$ to 2009 ( $n=13 ; 31.7 \%)$, and 2010 to present $(n=26 ; 63.4 \%)$. Moreover, most genomics courses were offered to medical students $(n=14 ; 34.1 \%)$ and pharmacy students $(n=13 ; 31.7 \%)$. Other participants included nursing students $(n=5 ; 12.2 \%)$, physician assistant students $(n=2 ; 4.9 \%)$, health information management students $(n=2 ; 4.9 \%)$, public health students $(n=1 ; 2.4 \%)$, and students with different majors (e.g., molecular medicine, nutrition, nursing, and biology; $n=4 ; 9.8 \%$ ). The numbers of students in each course ranged from 10 to 2674 (mean = 275.85; median $=144.00 ; \mathrm{SD}=528.70$ ), and nearly two-thirds of articles $(n=28 ; 68.3 \%)$ had more than 100 students.

While most studies did not report the types of courses, ten courses $(24.4 \%)$ were reported as required curricula, three courses were described as elective $(7.3 \%)$, and two courses (4.9\%) were labeled as both required and elective/extra credit. For example, one nationwide pharmacogenomics curriculum was characterized by Lee et al. as required in some colleges while elective in others. ${ }^{42}$ Nearly half of the courses $(n=20$; $48.8 \%$ ) were taught with more than one teaching method (e.g., in-class lectures, videos, computer labs, and self-genotyping exercise). The length of courses ranged from one-time lecture to full semester.

Regarding the theoretical framework of the curriculum, most curricula $(n=28 ; 68.3 \%)$ did not include any theoretical model or framework. The remaining 13 courses (31.7\%) were based on various theories, such as Adult Learning Theory, Social Learning/Cognitive Theory, Theory of Planned Behavior, Diffusion of Innovations, Teach-the-Teacher model, and Bloom's Taxonomy of Learning. While the content of each curriculum was not identical, the content was divided into 19 topics. These included basic genetics, such as general genetic concepts, genes, and chromosomes $(n=33 ; 80.5 \%)$; genetic risk assessment $(n=28 ; 66.7 \%)$; ethical, legal, and social 
Table 1 Frequency distributions of methodological quality among reviewed articles $(N=41)$

\begin{tabular}{|c|c|c|c|c|}
\hline \multirow[t]{2}{*}{$\begin{array}{l}\text { Methodological } \\
\text { criterion }\end{array}$} & \multirow[t]{2}{*}{ Description } & \multirow[t]{2}{*}{ Score } & \multicolumn{2}{|c|}{$\begin{array}{l}\text { Distribution } \\
\text { of } \\
\text { characteristics }\end{array}$} \\
\hline & & & $n$ & $\%$ \\
\hline \multirow[t]{4}{*}{ Sample size } & Not reported & 0 & 0 & 0.0 \\
\hline & $\begin{array}{l}\text { Small sample size } \\
(<100)\end{array}$ & 1 & 13 & 31.7 \\
\hline & $\begin{array}{l}\text { Medium sample size } \\
(>100 \text { and }<300)\end{array}$ & 2 & 19 & 46.3 \\
\hline & $\begin{array}{l}\text { Large sample size } \\
(\geq 300)\end{array}$ & 3 & 9 & 22.0 \\
\hline \multirow[t]{2}{*}{$\begin{array}{l}\text { Theoretical basis of } \\
\text { the curriculum }\end{array}$} & $\begin{array}{l}\text { Did not present } \\
\text { theoretical framework }\end{array}$ & 0 & 28 & 68.3 \\
\hline & $\begin{array}{l}\text { Presented theoretical } \\
\text { framework }\end{array}$ & 1 & 13 & 31.7 \\
\hline \multirow{4}{*}{$\begin{array}{l}\text { Length or duration } \\
\text { of curriculum }\end{array}$} & Not reported & 0 & 6 & 14.6 \\
\hline & $\begin{array}{l}\text { One hour or less than } \\
\text { an hour }\end{array}$ & 1 & 5 & 12.2 \\
\hline & $\begin{array}{l}\text { Less than a day but } \\
\text { more than one hour }\end{array}$ & 2 & 7 & 17.1 \\
\hline & More than a day & 3 & 23 & 56.1 \\
\hline \multirow[t]{2}{*}{ Follow-up } & Not reported & 0 & 35 & 85.4 \\
\hline & Reported & 1 & 6 & 14.6 \\
\hline
\end{tabular}

implications (ELSI) of genomics $(n=23 ; 56.1 \%)$; genetic counseling ( $n=23 ; 54.8 \%)$; usage of genomics Internet databases, such as Online Mendelian Inheritance in Man (OMIM) and Pharmacogenomics Knowledgebase $(n=15$; $36.6 \%)$; Mendelian/genetic disorders $(n=15 ; 36.6 \%)$, pharmacogenomics/pharmacogenetics $(n=14 ; 34.1 \%)$; genomics disorders $(n=13 ; 31.7 \%)$; genome data analysis $(n=9$; $22.0 \%)$; genomics tools and technology $(n=9 ; 22.0 \%)$; population genetics $(n=4 ; 9.8 \%)$; reproductive genetics $(n$ $=3$; $7.3 \%)$; bioinformatics $(n=3 ; 7.3 \%)$; business aspects of the genomics field $(n=3 ; 7.3 \%)$; pediatric genetics $(n=2$; $4.9 \%)$; nutrigenomics $(n=1 ; 2.4 \%)$; immunogenetics $(n=1$; $2.4 \%)$; molecular genetics $(n=1 ; 2.4 \%)$; and sexual genetics $(n=1 ; 2.4 \%)$.

\section{The evaluation of genomics education courses}

The courses were evaluated using cross-sectional/descriptive design $(n=15 ; 36.6 \%)$, pre- and post-test design $(n=22$; $53.7 \%)$, quasi-experimental design $(n=2 ; 4.9 \%)$, and experimental/randomized control trial $(n=2 ; 4.9 \%)$. Data were obtained via various methods such as pre- and post-test questionnaires, course evaluation surveys, examinations, quizzes, laboratory reports, in-class exercises, essays, research papers, self-reflective journals, research projects, focus groups, and discussion boards. For the most advanced statistical analysis used, more than half of the studies $(n=26 ; 63.4 \%)$ analyzed the data using inferential statistics without controlling for covariates, such as paired $t$ test, chi-square, and Wilcoxon signed-rank test. The remaining studies utilized univariate statistics or qualitative methods $(n=15 ; 36.6 \%)$.

\section{Evaluation findings}

The evaluation findings were outlined according to knowledge, self-efficacy, attitudes, intention, comfort level, motivations, behavior, and course feedback. Detailed results of major findings were outlined in Table S1.

\section{Student performance}

Knowledge. The majority of the studies ( $n=36 ; 87.8 \%)$ reported students' genetics/genomics knowledge as an evaluation outcome. Of these 36 studies, 22 studies reported statistically significant increases in knowledge after the course, one study did not find statistical significance, and 13 studies reported only descriptive results for knowledge. For example, in a pharmacogenomics course delivered to 310 doctorate of pharmacology students, Nickola et al. ${ }^{39}$ found significant increases from pre- to post-test in students' knowledge of genomics and the NCHPEG genomics competencies. ${ }^{39}$ Another study conducted by Magee et al. ${ }^{22}$ among 120 firstyear medical students indicated that all students showed sufficient knowledge and passed the genetics-based problem sets after the course. ${ }^{22}$ Furthermore, follow-up outcomes for genetics/genomics knowledge were reported in only four studies among which two studies noticed that their students' knowledge decreased in 1 and 2 years posteducation, respectively. For instance, Greb et al. ${ }^{31}$ reported that at the 2year follow-up, $88 \%$ of the medical students failed the genetics section on the observed structured clinical examination (OSCE) at the end of their third year of medical school; particularly, less than a quarter of students correctly calculated genetic risks and collected family history in a genetic case study on that exam. ${ }^{31}$ Nevertheless, one study conducted by Goodson et al. ${ }^{38}$ reported a significant increase in knowledge score from baseline to 3-month follow-up among graduate health education students. ${ }^{38}$

Attitudes. Sixteen studies (39.0\%) reported outcomes on students' attitudes toward genetics/genomics and/or future clinical practice in genetics/genomics. Of these 16 articles, 8 reported statistically significant improvement in attitudes among students after the course, 3 did not find statistical significance for students' attitudes scores, and 5 reported descriptive findings. For example, Adams et al. ${ }^{45}$ found a significant change in the participating doctorate of pharmacy students' attitudes toward recommending pharmacogenomic testing to patients after the pharmacogenomics course. Furthermore, in a study on a web-based pharmacogenomics course conducted by Lee et al., ${ }^{42} 80 \%$ of the participating doctorate of pharmacy students nationwide believed that pharmacists should conduct patient education about pharmacogenomics testing. ${ }^{42}$ Follow-up data for attitudes were reported in only one study, in which the attitudes score regarding genomics among participating graduate health 
education students significantly increased from pretest to 3month follow-up. ${ }^{38}$

Self-efficacy. More than one-third of the studies $(n=14$; $34.1 \%)$ reported statistically significant changes in confidence levels in performing a variety of genetics tasks (e.g., genetic risk assessments, genetic counseling, and using genetic databases) as well as in implementing genetics/genomics competencies and skills. All studies found positive self-efficacy outcomes. For instance, Makransky et al. ${ }^{49}$ reported statistically significant increases in self-efficacy scores from pre- to post-test in performing various medical genetics activities among the participating undergraduate medical and molecular biomedical students. ${ }^{49}$ Moreover, self-efficacy was reported as a follow-up outcome in three studies. The study of Goodson et al. ${ }^{38}$ did not show statistically significant findings for self-efficacy at 3-month follow-up. However, in the study of McGovern et al., ${ }^{25}$ students' self-efficacy scores in pedigree drawing as well as genetic risk assessment and communication remained significantly higher than those of the control group at 6-month follow-up. Williams et al. ${ }^{48}$ also found that their students' self-efficacy scores in performing genetic competencies remained significantly higher at 9month follow-up compared with their pre-test scores.

Comfort level. Four studies (9.8\%) assessed educational outcomes on comfort level with integrating or practicing genetics and genomics in future clinical practice. All four studies found statistically significant changes in students' comfort level after completing the courses. In a web-based genetics course for nurse practitioner students, for instance, Whitt et al. $^{43}$ stated that students exhibited significant improvements in their comfort level to perform genetics competencies and apply them to clinical practice after the course. No follow-up data on comfort level were reported in the studies included in this review.

Intention. Three studies (7.3\%) in this review assessed intention as an evaluation outcome. Intention was examined by assessing students' willingness to apply genetic/ genomics knowledge and skills learned from their courses to their future clinical practice. Among the three studies, two indicated statistically significant increases in students' intention scores from pre- to post-test, and one study presented descriptive data with positive intention outcomes. For instance, in the web-based courses reported in Metcalf et al., ${ }^{34}$ students' intentions related to the practices of genetic testing and counseling in the future increased significantly from preto post-test among the 596 participating medical students. Follow-up data on students' intentions were mentioned in only one study, in which no statistical significance was found for students' intention scores at 3-month follow-up. ${ }^{38}$

Motivation. Only three (7.3\%) articles in this study provided evaluation outcomes related to students' motivation; one of these three studies reported statistically significant findings, while the other two presented only descriptive data on motivation. All three studies suggested that genetics/genomics education led to positive motivation among students regarding learning genetics and genomics. For instance, in a pharmacogenomics training reported in Krynetskiy et al., ${ }^{33}$ openended survey results showed that doctorate of pharmacy students expressed further interest in learning about pharmacogenomics after the course. ${ }^{33}$ In addition, Busstra et al. ${ }^{27}$ mentioned that $58-75 \%$ of participating students majoring in either nutrition and health or biotechnology in the Netherlands indicated a high motivation to study nutrigenomics at 1-year follow-up. ${ }^{27}$

Behavior. Only two studies (4.9\%) included in this review reported behavioral outcomes. In particular, at the University of Chicago, Waggoner et al. ${ }^{26}$ developed a curriculum focusing on the integration of genetics Internet databases into medical curriculum, which was delivered to 324 medical students. ${ }^{26}$ One-year follow-up data showed that $72 \%$ of the students still used genomics databases multiple times in their clinical practice. The other study conducted by Goodson et al. ${ }^{38}$ indicated that students' behavior score did not significantly change compared with the baseline data. ${ }^{38}$

\section{Course feedback}

Most studies ( $n=35 ; 85.4 \%)$ reported students' feedback for the genetics and genomics courses. All courses were rated positively overall; participating students perceived the courses to be helpful and would be likely to recommend those courses to their peers. For example, Bean et al. ${ }^{11}$ stated that most of the medical students agreed that the virtual laboratory sessions about genetic testing were useful and suitable as well as that the content and teaching approaches were effective. Only one study ${ }^{27}$ included follow-up data on course content related feedback; the course evaluation scores were above average at 1-year follow-up.

\section{MQS}

The average MQS for all 41 studies was 4.51 ( $\mathrm{SD}=1.47$; range $=1-7$ ), which was slightly above the mean (4.00) of the possible theoretical MQS (range $=0-8$ ). Specifically, the reviewed studies overall obtained good scores in the sample size and course duration. More than two-thirds of the studies had a sample size higher than 100 students $(n=28 ; 68.3 \%)$, and more than half of the courses were longer than a day $(n=23 ; 56.1 \%)$. Nevertheless, the majority of the curricula were not grounded from a theoretical framework $(n=28$; $68.3 \%)$ and did not report follow-up data $(n=35 ; 85.4 \%)$.

\section{DISCUSSION}

To the best of our knowledge, this study is the first to systematically review the existing genomics programs available to health professional students. A total of 41 peer-reviewed studies that met our inclusion criteria were identified and included in this systematic review. There was a dramatic increase 
in the number of publications over time, suggesting increased awareness and perceived importance of this topic in the health science field. Nevertheless, the majority of studies were conducted in the United States and were limited to certain few countries, including the United Kingdom, the Netherlands, Canada, and China. It is important for researchers and educators beyond those countries to incorporate genomics into their curricula for health professional students.

Results from our review indicate that most genomics educations were delivered to medical and pharmacy students. A potential explanation is that the field of genomics, including pharmacogenomics and personalized/precision medicine, has immediate and noticeable impacts on their practice. For instance, metabolism and dosages of some drugs differ among individuals due to genetic polymorphism; thus, knowledge of pharmacogenetics is important to maximize the benefits and minimize adverse events. ${ }^{59}$ The other possible reason is that the training in pharmacy and medical schools tend to be longer than other health professional or health science disciplines, which might allow more flexibility to diffuse genomics into their curricula. Given that the role of genomics has become more important in the health field, other professional fields, especially those that have not published any studies in this area (e.g., dentistry, physical therapy, occupational therapy, and speech therapy), may need to develop disciplinary-specific genomics curricula and further evaluate the effectiveness for their own students.

Of note, the 41 studies we reviewed reported course feedback $(n=35)$ as well as assessed behavior $(n=2)$ and other cognitive variables, including knowledge $(n=36)$, attitudes $(n=16)$, selfefficacy $(n=14)$, comfort level $(n=4)$, intention $(n=3)$, and motivation $(n=3)$. While collecting behavioral data was understandably challenging among students, obtaining both cognitive variables and course feedback was essential for evaluating the effectiveness of the courses. Moreover, although the majority of the reviewed studies reported enhanced knowledge as well as improved self-efficacy, attitudes, intention, comfort level, and motivation immediately after their genomics education, only six studies gathered follow-up data to assess the sustainability of these education effects. Therefore, future studies should not only collect behavior, cognitive variables, and course feedback information, but follow-up data are also needed for this body of literature.

The mean of the MQS for all reviewed studies was 4.51, which was slightly above the mean of the theoretical average (4.00). While the majority of the studies had more than 100 students in their programs, and the duration of their education was longer than a day, some areas still need improvement. Specifically, developing the curriculum based on a theoretical framework and collecting follow-up data are critical for this body of literature. Future researchers and educators may consider collaborating with statisticians in the planning the stage of genomics curriculum development to gather and present more robust findings.

Nearly half of the courses (48.8\%) utilized more than one teaching method to deliver the genomics curricula. Studies with only a single teaching strategy mainly utilized in-class didactic lectures to deliver genomics courses to their students. According to the Adult Learning Theory developed by Malcolm Knowles, students' learning process is maximized when multiple instructional strategies are adopted to meet the different learning styles and needs among their students. ${ }^{60-62}$ Incorporating various teaching strategies, such as a mixture of class lectures, case studies, laboratory exercises, and standardized patients, may be useful to facilitate better learning outcomes among students. Thus, it is important for future genomics courses to adopt a variety of teaching strategies to engage and enhance health professional students' learning in genomics.

Interestingly, an emerging pedagogical method we found in our systematic review was the inclusion of students' selfgenotyping as a classroom exercise. In particular, several studies in our review reported the utilization of students' own genotyping as an experiential learning technique. This teaching technique has been acknowledged in the literature. ${ }^{63}$ This approach successfully improved health professional students' knowledge, attitudes, counseling skills, interpretations of genetic tests, and considerations of the ELSI of genomics. If health professional students underwent personal genotyping, they might also better relate their personal experience to patients while discussing genetic test procedures and results. ${ }^{64}$ Nevertheless, ethical concerns regarding including self-genotyping in curricula may need to be addressed. Cautions may be taken for the potential psychological impacts of genotyping results on the students and their families particularly from disease susceptibility test results. Issues related to the confidentiality and anonymity of the students' genome data should also be considered. ${ }^{63}$ Providing adequate information to ensure students make informed decisions before performing genotyping experiments, teaching students the importance of confidentiality and anonymity issues, and offering genetic counseling and support may minimize these potential risks. ${ }^{63,65-68}$ Another potential solution may be to give students options to analyze their personal genome data or anonymous genome data from third-party donors (or cadavers) to minimize the potential harms while meeting the learning objectives in genomics. ${ }^{69,70}$

There are three main limitations to this study. First, we had to develop our own MQS based on past literature due to various study designs of the included articles in this review. Second, not all of the "curricula" reported in the articles we reviewed were full, semester-long courses. Thus, the teaching methods reported in such studies might be limited to the ones used for the delivery of their genomics curricula and not the entire course. Finally, we conducted an extensive literature search to include all studies on genomics education among health professional students. Yet, despite our best efforts, there might have been some studies that were overlooked during the searching process. In addition, some genomics courses might have been offered to health professional students as part of school curricula that have neither evaluated their curricula nor published their studies. 
Despite the above limitations, there are several remarkable strengths in our review. First, to the best of our knowledge, this is the first systematic review focusing on genomics education for health professional students majoring in diverse disciplines, such as medicine, nursing, allied health, pharmacology, and physician assistants. Second, our study reports the existing genomics curricula, their method of delivering at schools, and the evaluation methods and findings. Results from our study provide information on the quantity and quality of the existing genomics education curricula for health professional students. It may guide future researchers and educators to develop genomics curricula tailored to their targeted students. An open-access genomics education database may need to be developed, where genomics education articles and curricula can be shared and disseminated. Third, the MQS suggested that there is a need to improve this body of literature. This systematic review may help future researchers adopt more rigorous methodological approaches to plan and evaluate the outcomes of their education. Lastly, given that genomics education should start from early education, and science, technology, engineering, and mathematics (STEM) education is currently an evolving topic, conducting a systematic review for genomics education among high school students is desired in the future.

\section{ELECTRONIC SUPPLEMENTARY MATERIAL}

The online version of this article (https://doi.org/10.1038/s41436018-0386-9) contains supplementary material, which is available to authorized users.

\section{DISCLOSURE}

The authors declare no conflicts of interest.

\section{REFERENCES}

1. Rehm HL. Evolving health care through personal genomics. Nat Rev Genet. 2017;18:259-267.

2. Khoury MJ, Galea S. Will precision medicine improve population health? JAMA. 2016;316:1357-1358.

3. Roberts MC, Kennedy AE, Chambers DA, Khoury MJ. The current state of implementation science in genomic medicine: opportunities for improvement. Genet Med. 2017;19:858-863.

4. Manolio TA, Chisholm RL, Ozenberger B, et al. Implementing genomic medicine in the clinic: the future is here. Genet Med. 2013;15:258-267.

5. Cashion A. The importance of genetics education for undergraduate and graduate nursing programs. J Nurs Educ. 2009;48:535-536.

6. National Coalition for Health Professional Education in Genetics. Core competencies for all health professionals 2007. https://www.jax.org/ education-and-learning/clinical-and-continuing-education/ccep-noncancer-resources/core-competencies-for-health-care-professionals. Accessed 9 October 2018.

7. Jenkins J, Calzone KA. Establishing the essential nursing competencies for genetics and genomics. J Nurs Scholarsh. 2007;39:10-16.

8. Cragun D, Lewis C, Camperlengo L, Pal T. Hereditary cancer: example of a public health approach to ensure population health benefits of genetic medicine. Healthcare. 2016;4:6.

9. Hyland K, Dasgupta S, Garber KB, et al. Medical school core curriculum in genetics 2013. http://media.wix.com/ugd/3a7b87 7064376a9eb346cfa1b85bc2f137c48f.pdf. Accessed 9 October 2018.
10. Chen L-S, Kwok O-M, Goodson P. US health educators' likelihood of adopting genomic competencies into health promotion. Am J Public Health. 2008;98:1651-1657.

11. Bean L, Fridovich-Keil J, Hegde M, Rudd MK, Garber KB. The virtual diagnostic laboratory: a new way of teaching undergraduate medical students about genetic testing. Genet Med. 2011;13:973-977.

12. Talwar D, Tseng T-S, Foster M, Xu L, Chen L-S. Genetics/genomics education for nongenetic health professionals: a systematic literature review. Genet Med. 2017;19:725-732.

13. Garrard J. Health sciences literature review made easy. Burlington, VT: Jones \& Bartlett Publishers; 2013.

14. MedEdPORTAL. Journal of the Medical Library Association: JMLA 2016;104:250-2. https://www.ncbi.nlm.nih.gov/pmc/articles/PMC4915653/. Accessed 14 December 2018.

15. Wongpakaran N, Wongpakaran T, Wedding D, Gwet KL. A comparison of Cohen's Kappa and Gwet's AC 1 when calculating inter-rater reliability coefficients: a study conducted with personality disorder samples. BMC Med Res Methodol. 2013;13:61.

16. Buhi ER, Goodson P. Predictors of adolescent sexual behavior and intention: a theory-guided systematic review. J Adolesc Health. 2007:40:4-21.

17. Suther S, Goodson P. Barriers to the provision of genetic services by primary care physicians: a systematic review of the literature. Genet Med. 2003;5:70-76.

18. Chen L-S, Goodson P. Factors affecting decisions to accept or decline cystic fibrosis carrier testing/screening: a theory-guided systematic review. Genet Med. 2007;9:442-450.

19. Moore CM, Barnett DR. A problem-based learning approach to teaching medical genetics. Am J Hum Genet. 1992;51:930-935.

20. Teague KE, Brown JA, Meyer JM, et al. Teaching efficacy of a medical education module on genetic testing for cancer. J Cancer Educ. 1996;11:196-202.

21. Miedzybrodzka Z, Hamilton NM, Gregory $H$, et al. Teaching undergraduates about familial breast cancer: comparison of a computer assisted learning (CAL) package with a traditional tutorial approach. Eur J Hum Genet. 2001;9:953-956.

22. Magee J, Gordon Jl, Whelan A. Bringing the human genome and the revolution in bioinformatics to the medical school classroom: a case report from Washington University School of Medicine. Acad Med. 2001;76:852-855.

23. Cragun DL, Couch SC, Prows CA, Warren NS, Christianson CA. A success of a genetics educational intervention for nursing and dietetic students: a model for incorporating genetics into nursing and allied health curricula. J Allied Health. 2005;34:90-96.

24. Brazeau DA, Brazeau GA. A required course in human genomics, pharmacogenomics, and bioinformatics. Am J Pharm Educ. 2006;70:125.

25. McGovern MM, Johnston M, Brown K, Zinberg R, Cohen D. Use of standardized patients in, undergraduate medical genetics education. Teach Learn Med. 2006;18:203-207.

26. Waggoner DJ, Martin CL. Integration of internet-based genetic databases into the medical school pre-clinical and clinical curriculum. Genet Med. 2006;8:379-382.

27. Busstra MC, Hartog R, Kersten S, Müller M. Design guidelines for the development of digital nutrigenomics learning material for heterogeneous target groups. Adv Physiol Educ. 2007;31:67-75.

28. LeLacheur S, Straker H, Macri CJ. Evaluation of a genetics curriculum for physician assistant students. J Physician Assist Educ. 2007;18:44-46.

29. Newcomb P, Riddlesperger $K$. Using improvisational theater to teach genetics concepts. Nurse Educ. 2007;32:227-230.

30. O'Brien TJ, Goodsaid F, Plack M, et al. Development of an undergraduate pharmacogenomics curriculum. Pharmacogenomics. 2009;10:1979-1986.

31. Greb AE, Brennan S, McParlane L, Page R, Bridge PD. Retention of medical genetics knowledge and skills by medical students. Genet Med. 2009;11:365-370.

32. Knoell DL, Johnston JS, Bao S, Kelley KA. A genotyping exercise for pharmacogenetics in pharmacy practice. Am J Pharm Educ. 2009;73:43.

33. Krynetskiy E, Calligaro IL. Introducing pharmacy students to pharmacogenomic analysis. Am J Pharm Educ. 2009;73:71.

34. Metcalf MP, Tanner TB, Buchanan. A Effectiveness of an online curriculum for medical students on genetics, genetic testing and counseling. Med Educ Online. 2010;15:4856.

35. Ludwig B, Zhou L, Watzlaf $\vee$, Abdelhak M. Adding a genomic healthcare component to a health information management curriculum. Perspect Health Inf Manag. 2010;7:1b. 
36. Springer JA, lannotti NV, Kane MD, Haynes $K$, Sprague JE. Pharmacogenomics training using an instructional software system. Am J Pharm Educ. 2011;75:32.

37. Zhou L, Watzlaf V, Abdelhak M. Flexible approaches for teaching computational genomics in a health information management program. Perspect Health Inf Manag. 2013;10:1b.

38. Goodson P, Chen L, Muenzenberger A, Xu L, Jung E. Genomics education for health educators in Texas: the family health history training program. Public Health Genomics. 2013;16:233-240.

39. Nickola TJ, Munson AM. Pharmacogenomics primer course for first professional year pharmacy students. Pharmacogenomics. 2014;15:39-48.

40. Diehl AC, Reader L, Hamosh A, Bodurtha JN. Horizontal integration of OMIM across the medical school preclinical curriculum for early reinforcement of clinical genetics principles. Genet Med. 2015;17:158-163.

41. Munson A, Pierce R. Flipping content to improve student examination performance in a pharmacogenomics course. Am J Pharm Educ. 2015;79:103.

42. Lee KC, Hudmon KS, Ma JD, Kuo GM. Evaluation of a shared pharmacogenomics curriculum for pharmacy students. Pharmacogenomics. 2015;16:315-322.

43. Whitt KJ, Macri C, O'Brien TJ, Wright S. Improving nurse practitioners' competence with genetics: effectiveness of an online course. J Am Assoc Nurse Pract. 2015;28:151-159.

44. Calinski DM, Kisor DF. An interdisciplinary experience focused on harmacogenetics: engaging pharmacy and physician assistant students in conversations about antiplatelet therapy with respect to CYP2C19 genotype. Innov Pharm. 2016;7:1.

45. Adams SM, Anderson KB, Coons JC, et al. Advancing pharmacogenomics education in the core PharmD curriculum through student personal genomic testing. Am J Pharm Educ. 2016;80:3.

46. Jamie K, Bows H, Gill J. Integration of pharmacogenetic principles as a core thread in the undergraduate pharmacy curriculum. Pharm Educ. 2016;16:64-66.

47. Weitzel KW, McDonough CW, Elsey AR, Burkley B, Cavallari LH, Johnson JA. Effects of using personal genotype data on student learning and attitudes in a pharmacogenomics course. Am J Pharm Educ. 2016;80:122.

48. Williams T, Dale R. A partnership approach to genetic and genomic graduate nursing curriculum: report of a new course's impact on student confidence. J Nurs Educ. 2016;55:574-578.

49. Makransky G, Bonde MT, Wulff JS, et al. Simulation based virtual learning environment in medical genetics counseling: an example of bridging the gap between theory and practice in medical education. BMC Med Educ. 2016;16:98

50. Gunder-McClary DHSC M, Lorilee $H$. Integrating online genetics into existing physician assistant curriculum - the experience at Nova Southeastern University. Internet J Allied Health Sci Pract. 2016;14:13.

51. Xu X-F, Wang Y, Wang Y-Y, Song M, Xiao W-G, Bai Y. Role-playing is an effective instructional strategy for genetic counseling training: an investigation and comparative study. BMC Med Educ. 2016;16:235.
52. Frick $A$, Benton $C S$, Scolaro $\mathrm{KL}$, et al. Transitioning pharmacogenomics into the clinical setting: training future pharmacists. Front Pharmacol. 2016;7:241.

53. St-Martin G, Bedard A, Nelmes J, Bedard JE. Preparing nurses for genetic medicine: integration of a brief education session in an undergraduate nursing curriculum. J Nurs Educ. 2017;56:170-173.

54. Remsberg CM, Bray BS, Wright SK, et al. Design, implementation, and assessment approaches within a pharmacogenomics course. Am J Pharm Educ. 2017;81:11.

55. Thatcher J, Canfield P, Bauer L, Griffith, Brian N. Pedigree analysis: a team-based learning activity. MedEdPORTAL. 2017;13:10557.

56. Dasgupta S. Medical genetics ethics case collection: discussion materials for medical students in the genomic era. MedEdPORTAL. 2017; 13:10562.

57. Jin H, Dasgupta S. Genetics in LGB assisted reproduction: two flipped classroom, progressive disclosure cases. MedEdPORTAL. 2017;13:10607.

58. Kronk R, Colbert A, Lengetti E. Assessment of a competency-based undergraduate course on genetic and genomics. Nurse Educ. 2017;43:201-205.

59. Kadafour M, Haugh R, Posin M, Kayser SR, Shin J. Survey on warfarin pharmacogenetic testing among anticoagulation providers. Pharmacogenomics. 2009;10:1853-1860.

60. Knowles MS. The modern practice of adult education. Vol 41. New York: New York Association Press; 1970.

61. Knowles MS. Andragogy: adult learning theory in perspective. Community Coll Rev. 1978;5:9-20.

62. Knowles MS. Andragogy in action. San Francisco, CA: Jossey-Bass; 1984.

63. Garber KB, Hyland K, Dasgupta S. Participatory genomic testing as an educational experience. Trends Genet. 2016;32:317-320.

64. Boguski MS, Boguski RM, Berman MR. Personal genotypes are teachable moments. Genome Med. 2013;5:22.

65. Åhman A, Runestam K, Sarkadi A. Did I really want to know this? Pregnant women's reaction to detection of a soft marker during ultrasound screening. Patient Educ Couns. 2010;81:87-93.

66. Bernhardt BA, Soucier D, Hanson K, Savage MS, Jackson L, Wapner RJ. Women's experiences receiving abnormal prenatal chromosomal microarray testing results. Genet Med. 2013;15:139-145.

67. Kleinveld JH, Ten Kate LP, van den Berg M, van Vugt JM, Timmermans DR. Does informed decision making influence psychological outcomes after receiving a positive screening outcome? Prenat Diagn. 2009;29:271-273.

68. Sanderson SC, Linderman MD, Zinberg R, et al. How do students react to analyzing their own genomes in a whole-genome sequencing course? Outcomes of a longitudinal cohort study. Genet Med. 2015; 17:866-874

69. Sanderson SC, Linderman MD, Kasarskis A, et al. Informed decisionmaking among students analyzing their personal genomes on a whole genome sequencing course: a longitudinal cohort study. Genome Med. 2013;5:113

70. Gerhard GS, Paynton B, Popoff SN. Integrating cadaver exome sequencing into a first-year medical student curriculum. JAMA. 2016:315:555-556. 